\title{
The Purine Nucleotide Cycle
}

\section{A PATHWAY FOR AMMONIA PRODUCTION IN THE RAT KIDNEY}

\author{
Ronald T. Bogusky, LeaH M. Lowenstein, and John M. LoWenstein \\ From the Department of Medicine, Boston University School of Medicine, \\ Boston, Massachusetts 02118, and the Graduate Department of Biochemistry, \\ Brandeis University, Waltham, Massachusetts 02154
}

\begin{abstract}
A в S T R A C T Particle-free extracts prepared from kidney cortex of rat catalyze the formation of ammonia via the purine nucleotide cycle. The cycle generates ammonia and fumarate from aspartate, using catalytic amounts of inosine monophosphate, adenylosuccinate, and adenosine monophosphate. The specific activities of the enzymes of the cycle are $1.27 \pm 0.27 \mathrm{nmol} / \mathrm{mg}$ protein per $\min (\mathrm{SE})$ for adenylosuccinate synthetase, $1.38 \pm 0.16$ for adenylosuccinase, and $44.0 \pm 3.3$ for AMP deaminase.

Compared with controls, extracts prepared from kidneys of rats fed ammonium chloride for 2 days show a $60 \%$ increase in adenylosuccinate synthetase and a threefold increase in adenylosuccinase activity, and a greater and more rapid synthesis of ammonia and adenine nucleotide from aspartate and inosine monophosphate. Extracts prepared from kidneys of rats fed a potassiumdeficient diet show a twofold increase in adenylosuccinate synthetase and a threefold increase in adenylosuccinase activity. In such extracts the rate of synthesis of ammonia and adenine nucleotide from aspartate and inosine monophosphate is also increased.

These results show that the reactions of the purine nucleotide cycle are present and can operate in extracts of kidney cortex. The operational capacity of the cycle is accelerated by ammonium chloride feeding and potassium depletion, conditions known to increase renal ammonia excretion.

Extracts of kidney cortex convert inosine monophosphate to uric acid. This is prevented by addition of allopurinol or 1-pyrophosphoryl ribose 5-phosphate to the reaction mixture.
\end{abstract}

Received for publication 17 June 1974 and in revised form 24 February 1976.

\section{INTRODUCTION}

The kidney plays a major role in the maintenance of acid-base balance, largely by the production of ammonia which diffuses into the tubular fluid where it combines with hydrogen ions (1). The resulting ammonium ions are nondiffusible and are excreted in the urine. Part of the renal ammonia is derived from the amide group of glutamine via the glutaminase reaction $(2,3)$. The remainder is currently believed to be derived largely from $\alpha$-amino groups of amino acids by transamination to $\alpha$-ketoglutarate (1), followed by oxidative deamination of the resulting glutamate via the glutamate dehydrogenase reaction (4). We report below that extracts of rat kidney cortex can catalyze the formation of ammonia via the purine nucleotide cycle, a sequence of reactions that results in the production of ammonia and fumarate from aspartate (5): ${ }^{1}$

$$
\begin{gathered}
\mathrm{AMP}+\mathrm{H}_{2} \mathrm{O} \rightarrow \mathrm{IMP}+\mathrm{NH}_{3} \\
\mathrm{IMP}+\mathrm{GTP}+\text { aspartate } \rightarrow \\
\text { adenylosuccinate }+\mathrm{GDP}+\mathrm{P}_{1} \\
\text { Adenylosuccinate } \rightarrow \text { AMP }+ \text { fumarate. }
\end{gathered}
$$

The enzymes that catalyze the reactions of the cycle are adenylate deaminase $(a)$, adenylosuccinate synthetase $(b)$, and adenylosuccinase $(c)$. The net reaction for one turn of the cycle is:

$$
\begin{aligned}
& \text { Aspartate }+\mathrm{GTP}+\mathrm{H}_{2} \mathrm{O} \rightarrow \\
& \text { fumarate }+\mathrm{GDP}+\mathrm{P}_{1}+\mathrm{NH}_{3} .
\end{aligned}
$$

${ }^{1}$ Abbreviations used in this paper: GDP, guanosine diphosphate; GMP, guanosine monophosphate; GTP, guanosine triphosphate; IMP, inosine monophosphate; SAMP, adenylosuccinate. 
Activities of enzymes $a, b$, and $c$ are reported for kidney extracts prepared from control rats and from rats subjected to ammonium-chloride feeding and potassium depletion, conditions known to increase renal ammonia production (6).

\section{METHODS}

Approximately $4 \mathrm{~g}$ of rat kidney cortex was homogenized in $3 \mathrm{vol}$ by weight of $60 \mathrm{mM}$ potassium phosphate buffer, $\mathrm{pH} 7.7,2.0 \mathrm{mM}$ EDTA, and $1.0 \mathrm{mM}$ dithiothreitol at $4^{\circ} \mathrm{C}$ using a motor-driven glass homogenizer. The homogenate was allowed to stand on ice for $30 \mathrm{~min}$ and was then centrifuged at $31,000 \mathrm{~g}$ for $10 \mathrm{~min}$. The supernate so obtained was centrifuged at $105,000 \mathrm{~g}$ for $45 \mathrm{~min}$. The resulting highspeed supernate was subjected to gel filtration to remove endogenous substrates. $5 \mathrm{ml}$ of the high-speed supernate was placed on a column of Sephadex G-25 (coarse grade) with a gel bed of $1.5 \times 15 \mathrm{~cm}$, which had been equilibrated with a mixture containing $30 \mathrm{mM}$ potassium phosphate buffer, $\mathrm{pH} 7.2,200 \mathrm{mM} \mathrm{KCl}$, and $1.0 \mathrm{mM}$ dithiothreitol. The column was eluted with the same mixture. The first $15 \mathrm{ml}$ to be eluted contained no protein and was discarded. $1-\mathrm{ml}$ fractions were collected, and the three fractions containing the highest protein concentrations were pooled. The resulting protein extract contained about $15 \mathrm{mg}$ protein per $\mathrm{ml}$.

Unless otherwise indicated, reaction mixtures designed to demonstrate the operation of the purine nucleotide cycle contained $0.1 \mathrm{ml}$ protein extract, $50 \mathrm{mM} \mathrm{KCl}, 0.16 \mathrm{mM}$ dithiothreitol, $0.25 \mathrm{mg}$ creatine phosphokinase, $16 \mathrm{mM}$ creatine phosphate, $0.3 \mathrm{mM}$ GTP, $0.5 \mathrm{mM}$ IMP, $4.0 \mathrm{mM}$ asparate, $5 \mathrm{mM}$ potassium phosphate buffer, $\mathrm{pH} 7.2,27 \mathrm{mM}$ imidazole- $\mathrm{HCl}$ buffer, $\mathrm{pH} 7.2,8.3 \mathrm{mM} \mathrm{MgCl}_{2}$, and $15 \mu \mathrm{g}$ yeast hexokinase ( $\mathrm{sp}$ act $50 \mathrm{U}$ per $\mathrm{mg}$ ) in a $0.6-\mathrm{ml}$ volume. The reaction mixture was placed in a cuvette with a $1-\mathrm{cm}$ light path into which was inserted a $0.9-\mathrm{cm}$ wide quartz slab that reduced the light path to $0.1 \mathrm{~cm}$. The reference cuvette contained the same substances but lacked asparate. Both cuvettes were held at $37^{\circ} \mathrm{C}$ in a water-jacketed cuvette holder. The conversion of IMP to adenine nucleotides was started by adding the protein extract. The conversion of AMP to IMP was initiated by adding 2-deoxyglucose in an amount equal to that of the creatine phosphate added originally. The reactions were followed by repeated spectral scanning from 310 to $250 \mathrm{~nm}$ using a Coleman 124 splitbeam spectrophotometer (Coleman Instruments Div., Oakbrook, Ill.). The recorder was zeroed at $310 \mathrm{~nm}$ after each scan. Fig. 1 shows tracings of a typical set of spectral scans obtained after starting the amination sequence by adding the protein extract. After amination had ceased, deamination was initiated by adding 2-deoxyglucose. The amounts of IMP, SAMP, and adenine nucleotide present during each spectral scan were calculated as described previously (7). ${ }^{2}$

\footnotetext{
${ }^{2}$ Creatine phosphate and creatine phosphokinase are added because they serve as a GTP-regenerating system. Adenylosuccinate synthetase is strongly inhibited by one of its end products, namely GDP. The inhibition is so strong that little or no reaction occurs unless the regenerating system is added. (No reaction may occur if the GTP that is added is contaminated with GDP.)

The calculation of the concentration of the three nucleotides is based on the absorbancies at 282,270 , and $262.5 \mathrm{~nm}$.
}

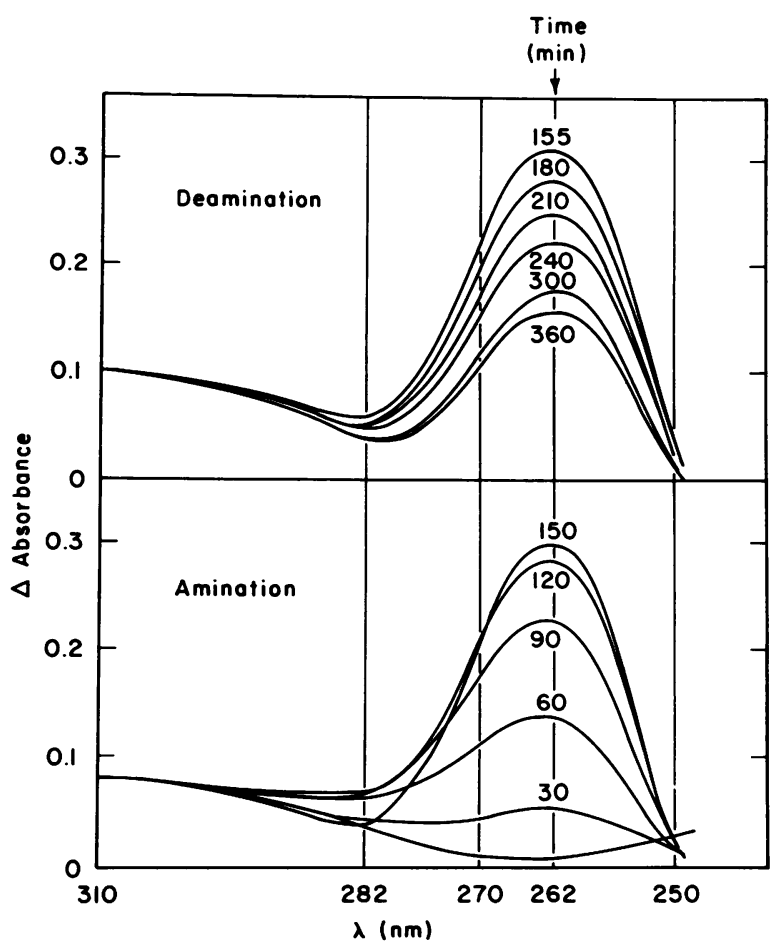

Figure 1 Operation of the purine nucleotide cycle in extracts of renal cortex. For details of the reaction mixture see Methods. The amination sequence was initiated by adding the protein extract; the spectral scans of this sequence are shown in the bottom panel. The deamination sequence was initiated by adding 2-deoxyglucose; the spectral scans of this sequence are shown in the top panel. These results were converted into adenylosuccinate and adenine nucleotide formed. (The scans are the actual results obtained during the experiment shown as solid lines in Fig. 5.)

Adenylate deaminase was measured by following the decrease in absorbance at $262.5 \mathrm{~nm}$ using a light path of $1 \mathrm{~mm}$.

For a $1 \mathrm{~mm}$ light path

$\Delta$ Adenylosuccinate $=\Delta \mathrm{A}_{2 \times 2} / 1.0$

$\Delta$ Adenine nucleotide $=\left(\Delta \mathrm{A}_{202.5}-1.14 \Delta \mathrm{A}_{252}\right) / 0.88$

$\Delta$ Adenine nucleotide $=\left(\Delta \mathrm{A}_{270}-1.5 \Delta \mathrm{A}_{282}\right) / 0.60$.

At $282 \mathrm{~nm}, \mathrm{IMP}$ and adenine nucleotide (AMP + ADP + ATP) absorb equally, and any change in absorbance at 282 $\mathrm{nm}$ is due only to changes in adenylosuccinate. At 262.5 and $270 \mathrm{~nm}$, the contribution of adenylosuccinate is first subtracted out by using an appropriate multiple of $\Delta \mathrm{A}_{23 y}$. The remainder represents the interconversion of IMP and adenine nucleotide, and is divided by the respective difference extinction coefficient to give the change in adenine nucleotide. The maximum difference in absorbance between IMP and AMP occurs at $262.5 \mathrm{~nm}$, and a smaller correction for adenylosuccinate has to be applied at 262.5 than at $270 \mathrm{~nm}$. The second equation is therefore more precise than the third, which is simply used as a check on the second to ensure that there is no distortion of the spectra. Hypoxanthine and uric acid formed were measured separately and were subtracted from the purine nucleotide cycle pool before making the calculations. For further details, such as extinction coefficients of the members of the purine nucleotide cycle, see reference 7 . 


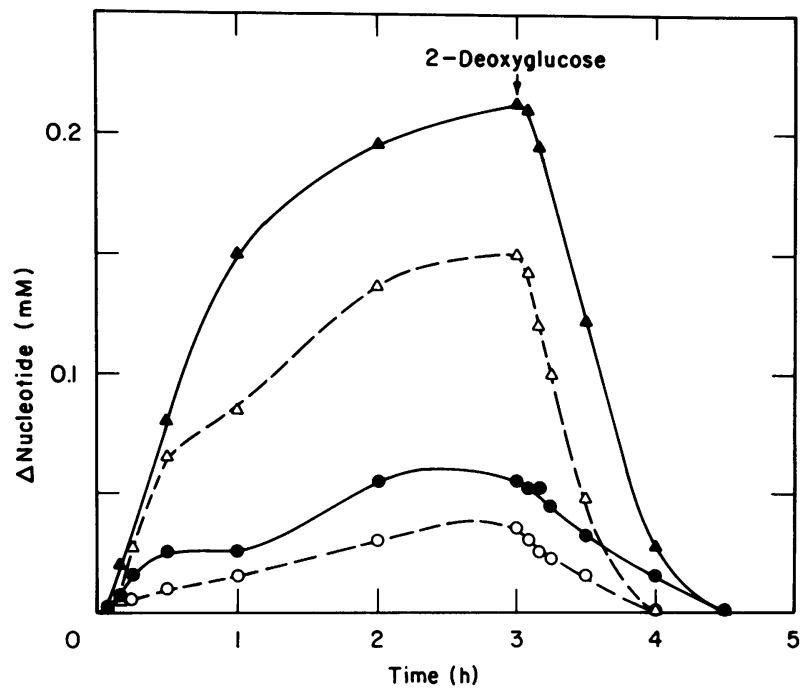

Figure 2 Operation of the purine nucleotide cycle in extracts of rat kidney cortex and the effect of EDTA in the extraction medium. The left renal cortices of two rats were homogenized in $60 \mathrm{mM}$ potassium phosphate buffer, $\mathrm{pH} 7.7$, and $1.0 \mathrm{mM}$ dithiothreitol; the right renal cortices were homogenized in the same buffer which also contained 2.0 $\mathrm{mM}$ EDTA. The homogenates were centrifuged, and each supernate was subjected to gel filtration as described under Methods. The reaction mixture contained $0.5 \mathrm{mM}$ IMP, 0.3 $\mathrm{mM}$ GTP, $4.0 \mathrm{mM}$ aspartate, $8.3 \mathrm{mM} \mathrm{MgCl}, 16 \mathrm{mM}$ creatine phosphate, $0.25 \mathrm{mg}$ creatine phosphokinase, $5 \mathrm{mM}$ phosphate buffer, $\mathrm{pH} 7.2,27 \mathrm{mM}$ imidazole- $\mathrm{HCl}$ buffer, $\mathrm{pH} 7.2$, and $15 \mu \mathrm{g}$ crystalline yeast hexokinase. The reaction was started by adding the kidney extract, $1.5 \mathrm{mg}$ protein, and was run in a final $0.6-\mathrm{ml}$ volume at $25^{\circ} \mathrm{C}$. 2-Deoxyglucose (equivalent to $16 \mathrm{mM}$ ) was added at the point indicated by the arrow. The operation of the purine nucleotide cycle was followed spectrophotometrically as described under Methods. The reference cuvette lacked aspartate. ( $\Delta$ and $\boldsymbol{\Delta}$, adenine nucleotides; $\bigcirc$ and $\bullet$, adenylosuccinate; broken lines, no EDTA; solid lines, $2.0 \mathrm{mM}$ EDTA added to extraction buffer.)

In assay $A$ the reaction mixture contained $27 \mathrm{mM}$ imidazole- $\mathrm{HCl}$ buffer, $\mathrm{pH} 7.2,50 \mathrm{mM} \mathrm{KCl}, 0.5 \mathrm{mM}$ AMP, 5 $\mathrm{mM}$ potassium phosphate buffer, $\mathrm{pH} 7.2$, and $0.1 \mathrm{ml}$ of protein extract, in a $0.6-\mathrm{ml}$ volume. The reaction was run at $37^{\circ} \mathrm{C}$. Assays were run in this manner because the enzyme extract contained $\mathrm{KCl}$ and potassium phosphate in amounts which optimized the stability of the enzymes which were assayed. However, these conditions were not optimum with respect to adenylate deaminase activity. Activities close to maximum reaction velocity were obtained in assay $B$ in which the reaction mixture contained $27 \mathrm{mM}$ imidazole- $\mathrm{HCl}$ buffer, $\mathrm{pH} 7.2,175 \mathrm{mM} \mathrm{KCl}, 2.0 \mathrm{mM}$ AMP, and enzyme. To assay the enzyme under these conditions, the protein extract was subjected to gel filtration under the conditions described above, except that phosphate buffer was omitted. $A$ comparison of assays $A$ and $B$ showed a ratio of activities (B/A) of 2.95 .

Adenylosuccinate synthetase was measured by following the change in absorbance at $259 \mathrm{~nm}$ using a light path of $1 \mathrm{~mm}$. The complete reaction mixture contained $27 \mathrm{mM}$ imidazole- $\mathrm{HCl}$ buffer, $\mathrm{pH}$ 7.2, $50 \mathrm{mM} \mathrm{KCl}, 8.3 \mathrm{mM}$
$\mathrm{MgCl}_{2}, 5 \mathrm{mM}$ potassium phosphate buffer, $\mathrm{pH} 7.2,0.16 \mathrm{mM}$ dithiothreitol, $0.25 \mathrm{mg}$ creatine phosphokinase, $16 \mathrm{mM}$ creatine phosphate, $0.3 \mathrm{mM}$ GTP, $0.5 \mathrm{mM}$ IMP, $4.0 \mathrm{mM}$ aspartate, and $0.1 \mathrm{ml}$ of protein extract in a final $0.6-\mathrm{ml}$ volume. The temperature was $37^{\circ} \mathrm{C}$.

Adenylosuccinase was measured by following the change in absorbance at $282 \mathrm{~nm}$ using a light path of $1 \mathrm{~mm}$. The complete reaction mixture contained $27 \mathrm{mM}$ imidazole- $\mathrm{HCl}$ buffer, $\mathrm{pH} 7.2,50 \mathrm{mM} \mathrm{KCl}, 8.3 \mathrm{mM} \mathrm{MgCl}, 5 \mathrm{mM}$ potassium phosphate buffer, $\mathrm{pH} 7.2,0.16 \mathrm{mM}$ dithiothreitol, 0.5 $\mathrm{mM}$ SAMP, and $0.1 \mathrm{ml}$ of kidney extract in a final $0.6-\mathrm{ml}$ volume. The temperature was $37^{\circ} \mathrm{C}$.

Protein was determined by the method of Lowry et al. (8), uric acid by a modification of the method of Brown (9), hypoxanthine by the method of Kalckar (10), ammonia by the method of Seligson and Seligson (11), lactate by the method of Hohorst (12), and fumarate and malate by the method of Williamson and Corkey (13), except that the change in absorbance was measured spectrophotometrically instead of fluorometrically.

Animals were acid-loaded by administration of $20 \mathrm{mmol}$ ammonium chloride per $\mathrm{kg}$ body weight by gavage for 2 days. During this time the animals had access to food and water ad lib. 6-h urine samples were collected before and during the acid-loading period. Urinary ammonia (expressed as micromoles ammonia per milligram creatinine) rose from a control level of $14.1 \pm 2.4(\mathrm{SEM})(n=11)$ to $184 \pm 18$ and $270 \pm 23$ on the 1 st and 2 nd day of acid loading, respectively $(P<0.001)$. Other controls showed that an equivalent amount of ammonium carbonate produced $20.5 \pm 4.5 \mu \mathrm{mol}$ ammonia per $\mathrm{mg}$ creatinine on the $1 \mathrm{st}$ and 2 nd day of administration $(P>0.1)$.

Animals were made potassium-deficient by feeding them a diet low in potassium, $<0.1 \%$ potassium in the whole diet (General Biochemicals, Chagrin Falls, Ohio, catalog no. 170550), and giving them a solution of $0.9 \% \mathrm{NaCl}$ as drinking water for 10 days. In addition each rat received $1 \mathrm{mg}$ deoxycorticosterone acetate daily by subcutaneous injection. Under these conditions serum potassium concentrations fell from control values of $5.26 \pm 0.19$ (SEM) $\quad(n=$ 12) to $2.69 \pm 0.16 \mathrm{meq}$ per liter after 10 days of depletion $(P<0.001)$.

Male Sprague-Dawley rats $(250 \mathrm{~g})$ were obtained from Charles River Breeding Laboratories (Wilmington, Mass.). Adenylosuccinate was prepared for us by Vera Schultz, Biochemistry Department, Brandeis University. Adenosine $\alpha, \beta$-methylene diphosphonate was obtained from Miles Laboratories, Inc. (Elkhart, Ind.). All other biochemicals were obtained from Sigma Chemical Corp. (St. Louis, Mo.).

\section{RESULTS}

Activities of purine nucleotide cycle enzymes. The specific activities of adenylosuccinate synthetase and adenylosuccinase in the extracts prepared from renal cortex were $1.27 \pm 0.07(\mathrm{SE})(n=32)$ and $1.38 \pm 0.16$ $(n=30) \mathrm{nmol} / \mathrm{mg}$ protein per min, respectively. The specific activity of adenylate deaminase was $44.0 \pm 3.4$ $\mathrm{nmol} / \mathrm{mg}$ protein per $\min (n=25)$ when EDTA was omitted from the extraction medium. When $2 \mathrm{mM}$ EDTA was present during the extraction, the specific activity of adenylate deaminase was $4.95 \pm 0.65 \mathrm{nmol}$ $(n=14)$.

Effect of EDTA on operation of the purine nucleotide 


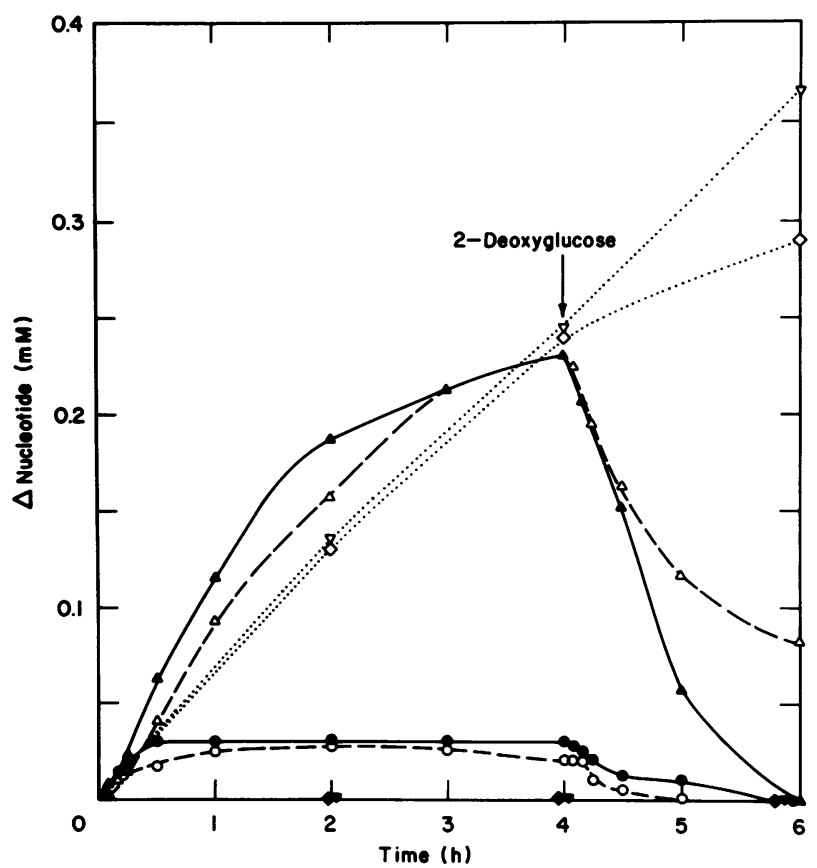

Figure 3 Effect of $0.5 \mathrm{mM}$ allopurinol on the operation of the purine nucleotide cycle. Kidney cortices of two rats were homogenized in $60 \mathrm{mM}$ potassium phosphate buffer, $\mathrm{pH}$ 7.7, $2.0 \mathrm{mM}$ EDTA, and $1.0 \mathrm{mM}$ dithiothreitol. The homogenate was centrifuged and $5 \mathrm{ml}$ of the resulting supernate was subjected to gel filtration as described under Methods. Another $5 \mathrm{ml}$ of the supernate was also subjected to gel filtration under the same conditions, except that the eluting buffer also contained $3.0 \mathrm{mM}$ allopurinol. The reaction mixture was as described in the legend to Fig. 2 for the extract prepared in the presence of $2 \mathrm{mM}$ EDTA. The operation of the purine nucleotide cycle was followed spectrophotometrically as described under Methods. Samples were also taken from the reference and test cuvettes for the determination of uric acid. ( $\Delta$ and $\boldsymbol{\Delta}$, adenine nucleotides; $\bigcirc$ and $\bullet$, adenylosuccinate; $\diamond$ and $\diamond$, uric acid in test cuvette; $\nabla$ and $\nabla$, uric acid in reference cuvette; open symbols, no allopurinol added to test and reference cuvettes; and solid symbols, $0.5 \mathrm{mM}$ allopurinol added to reaction mixtures of both test and reference cuvettes.) Note that no uric acid was formed when allopurinol was present. Solid, broken, and dotted lines are used to assist recognition.

cycle. Initial attempts to demonstrate the operation of the complete cycle in extracts of kidney cortex were frustrated by a loss of both adenine and hypoxanthine nucleotides from the system. We therefore investigated the conditions required to keep these nucleotides intact. An experiment demonstrating the operation of the purine nucleotide cycle is shown in Fig. 2. The cycle was initiated by the addition of extract. More adenine nucleotide accumulated when the extract was prepared in the presence of EDTA (solid lines) than in its absence (broken lines). This finding suggests that adenylate deaminase activity is inhibited by EDTA, or that less of the enzyme is extracted in the presence of EDTA than in its absence, or that EDTA reduces the loss of IMP by side reactions.

Effect of allopurinol. During the incubation of the kidney extract with the reaction mixture, a portion of the IMP was converted to uric acid (Fig. 3, open symbols). Formation of uric acid was prevented by the addition of $0.5 \mathrm{mM}$ allopurinol to the reaction mixture (Fig. 3 , solid symbols). However, the presence of allopurinol

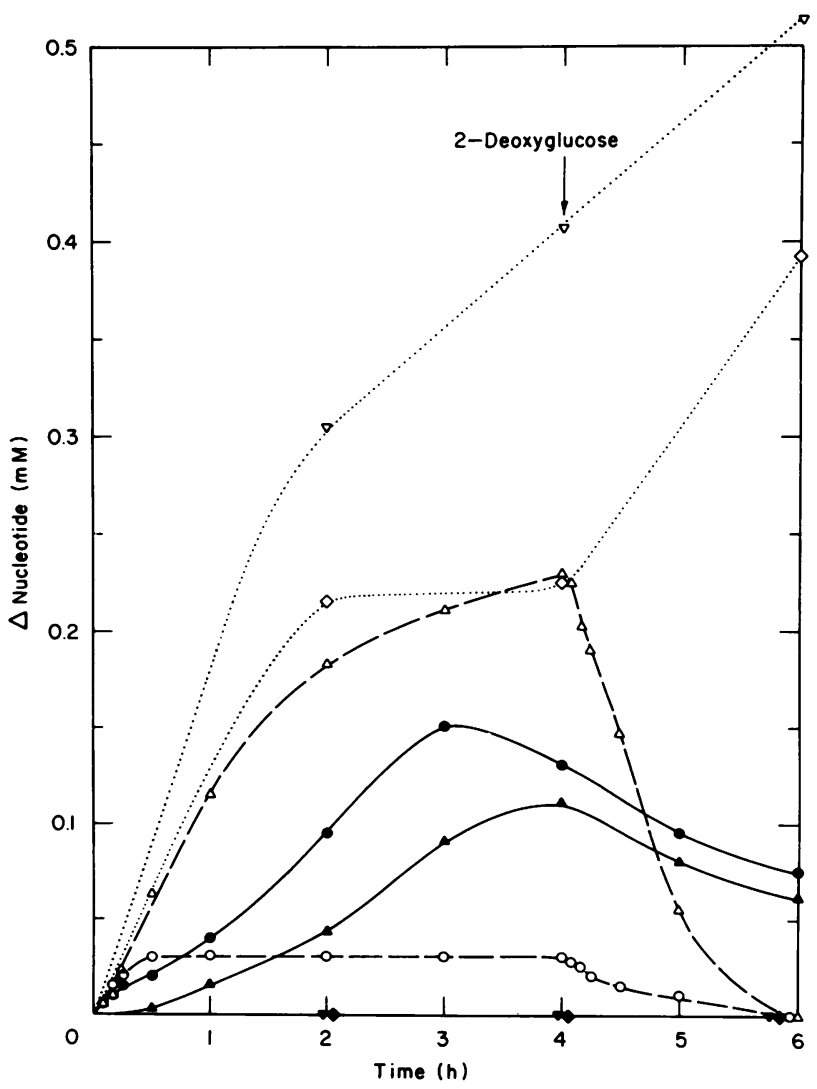

Figure 4 Effect of 1-pyrophosphoryl ribose 5-phosphate on the operation of the purine nucleatide cycle. Kidney cortices from two rats were homogenized in $60 \mathrm{mM}$ potassium phosphate buffer, $\mathrm{pH} 7.7,2.0 \mathrm{mM}$ EDTA, and 1.0 $\mathrm{mM}$ dithiothreitol. The homogenate was centrifuged, and the resulting supernate was subjected to gel filtration as described under Methods, except that the eluting mixture also contained $3.0 \mathrm{mM}$ allopurinol. The reaction mixture was as described in the legend to Fig. 2, except that it also contained $0.5 \mathrm{mM}$ allopurinol. The spectrophotometric assay for the purine nucleotide cycle was employed. In addition, samples of the reaction mixture were withdrawn at the times indicated and assayed for hypoxanthine. ( $\triangle$ and $\boldsymbol{\Delta}$, adenine nucleotides; $\bigcirc$ and $\bullet$, adenylosuccinate; $\diamond$ and $\diamond$, hypoxanthine in test cuvette; $\nabla$ and $\nabla$, hypoxanthine in reference cuvette; open symbols, no 1-pyrophosphoryl ribose 5-phosphate added to test and reference cuvettes; solid symbols, $0.8 \mathrm{mM}$ 1-pyrophosphoryl ribose 5-phosphate added to test and reference cuvettes.) Note that the amount of hypoxanthine formed in the presence of 1-pyrophosphoryl ribose 5-phosphate was zero. Solid, broken, and dotted lines are used to assist recognition. 


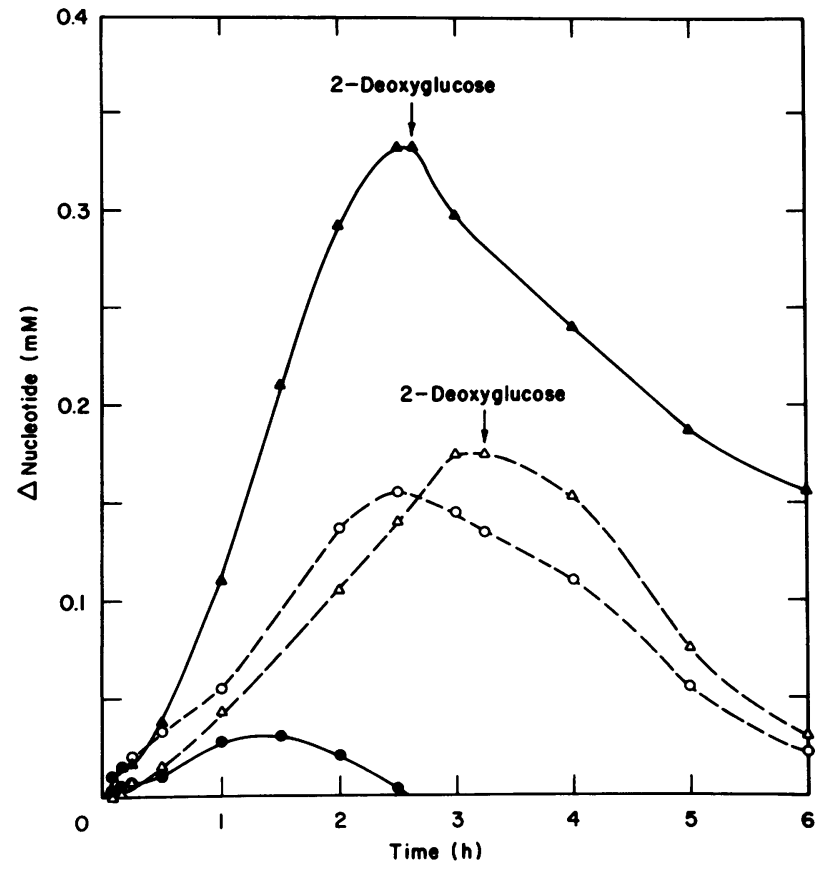

Figure 5 Effect of ammonium chloride feeding on the operation of the purine nucleotide cycle. A rat weighing 250 $\mathrm{g}$ was fed $20 \mathrm{mmol}$ ammonium chloride per $\mathrm{kg}$ body weight by gastric gavage daily for 2 days and was given drinking water ad lib. A sibling that did not receive $\mathrm{NH}_{4} \mathrm{Cl}$ served as control. Both animals were fed with Purina laboratory chow (Ralston Purina Co., St. Louis, Mo.). On the 2nd day the animals were killed, and extracts of their kidney cortices were prepared as described under Methods. The reaction mixture was as described in the legend to Fig. 2, except that both test and reference cuvettes contained 0.8 $\mathrm{mM}$ 1-pyrophosphoryl ribose 5-phosphate and $0.5 \mathrm{mM}$ allopurinol. The spectrophotometric assay for the purine nucleotide cycle was employed. ( $\Delta$ and $\boldsymbol{\Delta}$, adenine nucleotides; $\bigcirc$ and $\bullet$, adenylosuccinate; broken lines, control rat; and solid lines, $\mathrm{NH}_{4} \mathrm{Cl}$-fed rat.)

had relatively little effect on the rate of operation of the purine nucleotide cycle or on the extent to which its intermediates accumulated. Both adenine and guanine nucleotides were completely converted to uric acid after the reaction mixture had been allowed to stand at room temperature for $24 \mathrm{~h}$, even when allopurinol was present in the reaction mixture (not shown in Fig. 3). In the presence of $0.5 \mathrm{mM}$ allopurinol, hypoxanthine accumulated in the sample and reference curvettes at different rates (Fig. 4, dotted lines). This difference causes a distortion of the spectra.

Effect of 1-pyrophosphoryl ribose 5-phosphate. In the presence of $0.8 \mathrm{mM} 1$-pyrophosphoryl ribose 5-phosphate, no hypoxanthine accumulated over a 6 -h period (Fig. 4, solid symbols). The presence of 1-pyrophosphoryl ribose 5-phosphate resulted in an increased accumulation of adenylosuccinate and a decreased accumulation of adenine nucleotide during the amination phase of the experiment. One possible explanation for this observation is that 1-pyrophosphoryl ribose 5-phosphate somewhat inhibits adenylosuccinase.

The loss of purine nucleotides to nucleosides and purine bases was not inhibited by the addition of adenosine $\alpha, \beta$-methylene diphosphonate, indicating that the loss was not initiated by a $5^{\prime}$-nucleotidase inhibitable by this analogue (14).

Effect of ammonium chloride feeding. Protein extracts prepared from rats fed $20 \mathrm{mmol}$ ammonium chloride per $\mathrm{kg}$ body weight daily for 2 days showed a greater and more rapid accumulation of adenine nucleotide during tests for the operation of the purine nucleotide cycle than did untreated controls. Typical results obtained with paired rats are shown in Fig. 5. Other experiments showed that 3 days of ammonium chloride feeding produced a similar effect. Measurements of adenylosuccinate synthetase and adenylosuccinase showed that the activities of the enzymes were increased 1.6and 2.6-fold, respectively, in eight paired experiments (Table I). Four rats fed an amount of ammonium carbonate equivalent to the ammonium chloride given the other rats did not show a change in adenylosuccinase activity.

Ammonium chloride feeding resulted in an increase in ammonia production under cycling conditions (Table II). This increase was not observed in kidney extracts prepared from ammonium carbonate-fed rats.

Effect of potassium depletion. Operation of the purine nucleotide cycle in extracts prepared from kidney cortex of rats that had been kept on the potassium-deficient diet was compared with the operation of the cycle in extracts prepared from normal rats. Results of a typical experiment obtained with paired rats are shown in Fig. 6. Hypokalemia caused an increase in the rate of accumulation of adenine nucleotide and in the total amount accumulated (AMP + ADP + ATP). At the same time there was a considerable reduction in the amount of adenylosuccinate accumulated. Similar results were obtained in five other experiments. Adenyosuccinate synthetase and adenylosuccinase increased 1.8- and 2.7-fold in activity, respectively (Table I). Potassium depletion resulted in an increase in ammonia production under cycling conditions (Table II).

Ammonia production. Ammonia production did not start until the deamination phase of the cycle was initiated by adding 2-deoxyglucose. Six experiments, run under the conditions described in the legend to Fig. 6, showed a production of $0.56 \pm 0.9(\mathrm{SEM}) \mathrm{nmol} \mathrm{NH} / \mathrm{mg}$ protein per min.

As has already been stated, adenylosuccinate synthetase is strongly inhibited by one of its reaction products, namely GDP. This necessitates addition of creatine phosphate to regenerate GTP from GDP to demonstrate 
TABLE I

Activities of Purine Nucleotide Cycle Enzymes in Kidney Cortex of Normal, Acidotic, and Hypokalemic Rats

\begin{tabular}{|c|c|c|c|c|c|c|c|c|c|c|}
\hline \multirow{2}{*}{$\begin{array}{l}\text { Enzyme activity } \\
\text { measured }\end{array}$} & \multicolumn{2}{|c|}{ Normal rats } & \multicolumn{4}{|c|}{ Paired rats } & \multicolumn{4}{|c|}{ Paired rats } \\
\hline & & $n$ & Normal & Acidotic & $n$ & $P^{*}$ & Normal & Hypokalemic & $n$ & $P^{*}$ \\
\hline Adenylate deaminase & $\begin{array}{c}14.9 \pm 1.1 \\
\quad(44.0)\end{array}$ & 25 & $\begin{array}{c}11.4 \pm 2.5 \\
\quad(33.6)\end{array}$ & $\begin{array}{c}8.9 \pm 2.2 \\
(26.3)\end{array}$ & 6 & 0.1 & $\begin{array}{c}17.9 \pm 3.8 \\
(52.8)\end{array}$ & $\begin{array}{c}6.2 \pm 0.7 \\
(18.3)\end{array}$ & 7 & 0.02 \\
\hline \multicolumn{11}{|l|}{ Adenylosuccinate } \\
\hline synthetase & $1.27 \pm 0.07$ & 25 & $1.21 \pm 0.14$ & $1.92 \pm 0.21$ & 8 & 0.02 & $1.14 \pm 0.14$ & $2.08 \pm 0.39$ & 8 & 0.02 \\
\hline Adenylosuccinase & $1.38 \pm 0.16$ & 25 & $1.28 \pm 0.24$ & $3.27 \pm 0.51$ & 8 & 0.005 & $1.02 \pm 0.19$ & $2.76 \pm 0.53$ & 13 & 0.001 \\
\hline
\end{tabular}

Activities are expressed as nanomoles per milligram protein per minute, and are quoted as assayed at $\mathrm{pH} 7.2$. The assay conditions are described in the Methods section. Adenylosuccinate synthetase and adenylosuccinase activities were determined under conditions yielding rates close to $V_{\max }$. Adenylate deaminase activities were determined under conditions yielding $V_{\max } / 2.95$. The $V_{\max }$ values are quoted in parentheses; they were obtained by multiplying the measured rates by 2.95 .

* Paired $t$ test (30).

the operation of the complete cycle. Conversely, omission of the GTP-regenerating system can be used to demonstrate that ammonia production by the extract depends on the operation of adenylosuccinate synthetase. Table II shows ammonia production during one complete turn of the purine nucleotide cycle. In the presence of the GTP-regenerating system, little or no ammonia production occurred during the amination phase of the cycle, which was observed by running spectral scans. However, there was a rapid release of ammonia during the deamination phase of the cycle, which was also observed by running spectral scans. In controls which lacked creatine phosphate, spectral scans showed that neither the amination nor the deamination phase of the cycle occurred. Ammonia analyses of the controls showed an accumulation of approximately $0.1 \mathrm{mM}$ ammonia during the period which corresponded to the amination phase in the complete reaction mixture. The controls showed little additional accumulation of ammonia during the period corresponding to the deamination phase of the cycle in the complete reaction mixture. The simplest explanation for these observations is that when creatine phosphate is omitted, the GDP formed prevents production of ammonia via the purine nucleotide cycle by inhibiting adenylosuccinate synthetase. However, under these conditions GDP is degraded further to GMP and guanosine, which is then deaminated to xanthosine and ammonia. The correctness of this interpretation is supported by the observation that when kidney extracts were incubated with $0.1 \mathrm{mM}$ GTP alone, the amount of ammonia produced was about $0.1 \mathrm{mM}$, but this ammonia production was prevented by addition of creatine phosphate (Table II).

The fate of aspartate carbon. The combined operation of adenylosuccinate synthetase and adenylosuccinase results in the conversion of aspartate to fumarate. Previous studies with muscle extracts showed a stoichiometric relation between adenine nucleotide formed and malate plus fumarate formed during the reamination phase of the purine nucleotide cycle (7). This straightforward stoichiometry prevailed because there were no side reactions apart from the formation of malate from fumarate. In the case of kidney extracts, additional reactions occur which convert fumarate not only to malate but also to lactate. Under the experimental conditions described in the legend to Fig. 6, for $1.0 \mathrm{~mol}$ adenine nucleotide formed from IMP there was formed 0.089 mol fumarate, $0.25 \mathrm{~mol}$ malate, and $0.36 \mathrm{~mol}$ lactate (total $=0.70 \mathrm{~mol}$ ). The $0.30 \mathrm{~mol}$ of asparate carbon not accounted for presumably accumulated in other intermediates. Lactate was probably formed from malate via malate dehydrogenase, phosphoenolpyruvate carboxykinase, pyruvate kinase, and lactate dehydrogenase. $\mathrm{NAD}^{+}$was not added to the reaction mixture, but suff-

\section{TABLE II}

Ammonia Production by Extracts of Rat Kidney during a Single Turn of the Purine Nucleotide Cycle

\begin{tabular}{lcccc}
\hline & & \multicolumn{3}{c}{ Ammonia production, $m M$} \\
\cline { 4 - 5 } $\begin{array}{c}\text { Rats used for } \\
\text { preparing kidney } \\
\text { extract }\end{array}$ & $\begin{array}{c}\text { GTPen- } \\
\text { regen } \\
\text { erating } \\
\text { system }\end{array}$ & $\begin{array}{c}\text { Amina- } \\
\text { tion } \\
\text { phase }\end{array}$ & $\begin{array}{c}\text { Deamina- } \\
\text { tion } \\
\text { phase }\end{array}$ & $\Delta$ \\
\hline Controls & + & 0.01 & 0.21 & 0.20 \\
& - & 0.15 & 0.18 & 0.03 \\
Acidotic & + & 0.04 & 0.48 & 0.44 \\
& - & 0.13 & 0.14 & 0.01 \\
Hypokalemic & + & 0.01 & 0.38 & 0.37 \\
& - & 0.11 & 0.12 & 0.01 \\
Controls, extract & + & 0.01 & 0.01 & 0 \\
incubated with & - & 0.09 & 0.12 & 0.03 \\
GTP in absence of & & & & \\
aspartate and IMP & & & & \\
\hline
\end{tabular}

The complete reaction mixture was as described under Methods, except that the GTP concentration was $0.1 \mathrm{mM}$. The amination sequence was initiated by adding the protein extract. Reaction mixtures marked with a minus in the "GTP-regenerating system" column lacked creatine phosphate. 


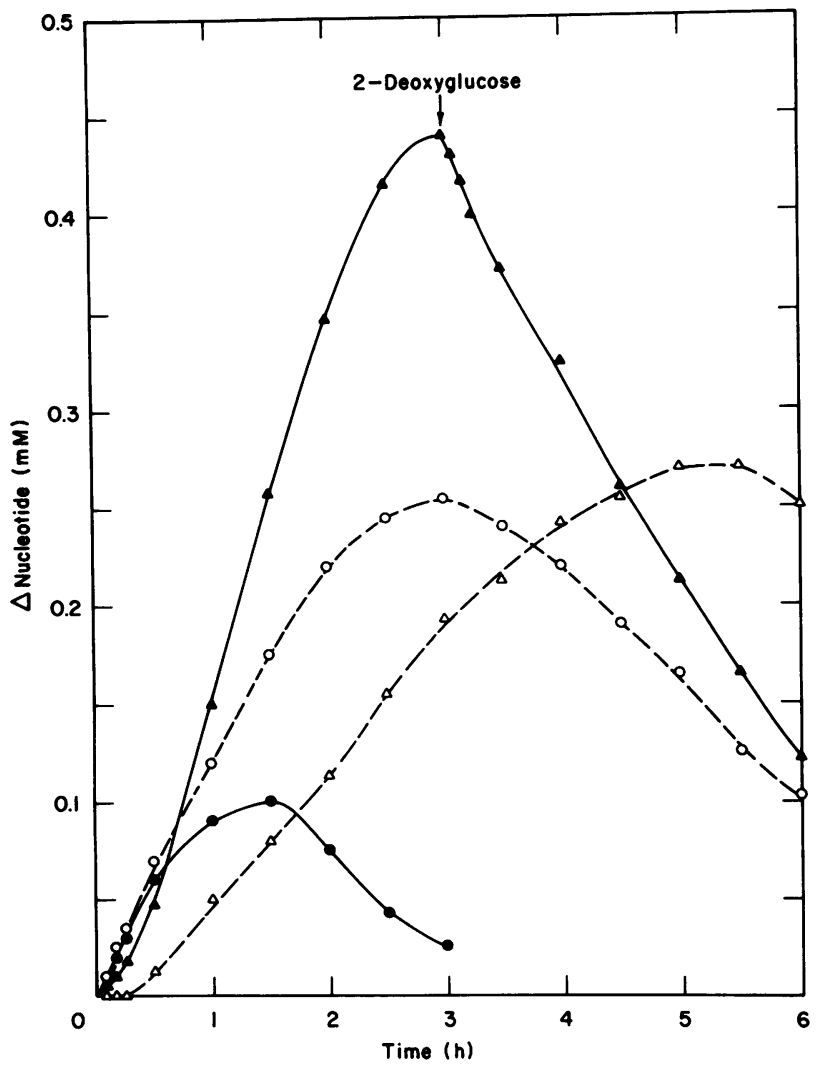

FIGURE 6 Effect of hypokalemia on the operation of the purine nucleotide cycle. A rat weighing $250 \mathrm{~g}$ was made hypokalemic by a daily injection of $1.0 \mathrm{mg}$ of deoxycorticosterone acetate for 10 days while being fed a low potassium diet and receiving $0.9 \% \mathrm{NaCl}$ as drinking water over the same period (serum potassium $=2.35$ mequiv per liter). A sibling received the regular laboratory diet and water for drinking. On the 11 th day of the treatment, the animals were killed and extracts of their kidney cortices were prepared as described under Methods. The reaction mixture was as described in the legend to Fig. 2, except that both test and reference cuvettes contained $0.8 \mathrm{mM} 1$-pyrophosphoryl ribose 5 -phosphate. The spectrophotometric assay for the purine nucleotide cycle was employed. ( $\Delta$ and $\boldsymbol{\Delta}$, adenine nucleotides; $\bigcirc$ and $\bullet$, adenylosuccinate; broken lines, control rat; and solid lines, hypokalemic rat.)

cient endogenous, enzyme-bound $\mathrm{NAD}^{+}$probably survived the gel filtration of the high-speed supernate to catalyze the dismutation between malate and lactate.

\section{DISCUSSION}

The currently accepted scheme for ammonia production by the kidney involves the conversion of glutamine to ammonia and glutanate via the glutaminase reaction, and the conversion of glutanate to ammonia and $\alpha$-ketoglutarate via the glutamate dehydrogenase reaction (4, 15-17). Another and probably minor pathway involves the transamination of glutamine and $\alpha$-ketoglutarate to yield $\alpha$-ketoglutaramate and glutamate, and the subse- quent deamidation of $\alpha$-ketoglutaramate to $\alpha$-ketoglutarate plus ammonia and the deamination of glutamate via the glutamate dehydrogenase reaction (17-19). Various theories exist as to what factors control ammonia production, but they all essentially attempt to explain how glutaminase and glutamate dehydrogenase can be deinhibited by removal of end products or inhibitors (17, 20-27). Thus the currently accepted scheme pivots on the assumption that glutamate dehydrogenase plays a primary role in ammonia formation from the $\alpha$-amino groups of amino acids.

Operation of the purine nucleotide cycle has been demonstrated in extracts of muscle $(7,28)$ and brain (29). The cycle may serve to maintain a high ratio of $[\mathrm{ATP}] /[\mathrm{ADP}]$, and is involved in the control of glycolysis (7). In addition it may serve in the control of the citric acid cycle and in the liberation of ammonia from $\alpha$-amino acids (5).

The experiments reported above demonstrate the production of ammonia from aspartate via the reactions of the purine nucleotide cycle in particle-free extracts of kidney cortex. High activities of glutamate-aspartate transaminase occur in every tissue (5), ensuring a rapid conversion of glutamate to aspartate and vice versa. Adenylosuccinate synthetase is strongly inhibited by GDP, a product of the reaction it catalyzes, but this inhibition can be avoided by employing a nucleoside triphosphate-regenerating system such as one consisting of creatine phosphokinase and creatine phosphate (5). The regenerating system also causes adenine nucleotide to be "trapped" as the triphosphate at the end of the amination phase of the cycle: IMP + aspartate $\rightarrow$ adenylosuccinate $\rightarrow$ AMP $\rightarrow$ ADP $\rightarrow$ ATP, and this prevents the deamination phase of the cycle from operating. One way in which deamination can be initiated is by the addition of 2-deoxyglucose, which, in conjunction with hexokinase and myokinase, leads to the conversion of ATP into ADP and AMP.

Acid loading and hypokalemia are accompanied by an increased output of ammonia by the kidney. Our results show that both conditions are associated with elevated activities of adenylosuccinate synthetase and adenylosuccinase (Table I). Experimentally induced hypokalemia causes a decrease in the activity of adenylate deaminase (Table I). However, it should be noted that even under these conditions, adenylate deaminase is still about three times more active than adenylosuccinase (Table I). (This comparison refers to the assays carried out at $\mathrm{pH}$ 7.2.) Of interest in this connection is a report that primary hypokalemic periodic paralysis in humans is associated with very low levels of adenylate deaminase in muscle (31). Administration of a load of carbohydrate to patients suffering from this disease can lead to sudden onsets of paralysis. In skeletal muscle 
the rate of ammonia production correlates well with the rate of glycolysis, although there is no stoichiometry between the two processes (5).

The possible contribution of the purine nucleotide cycle to ammonia production by the kidney can be estimated by comparison of our results with previously published data for the rat. The literature contains many reports of rates of ammonia production by kidney based on experiments with slices, perfused kidneys, and whole animals. Measurements performed in vitro commonly involved the addition of glutamine to the incubation mixture or perfusate. In such cases the glutamine added represented a large excess over the amount of ammonia produced during the experiment, and the amide group of glutamine was the major source of ammonia. Under such conditions it is difficult to assess the amounts of ammonia arising from other sources such as the $\alpha$-amino group of amino acids. An assessment of the relative contributions to ammonia production made by different nitrogen sources under physiological conditions has been made only for kidney of the dog; an average of $43 \%$ of the excreted ammonia was calculated to arise from glutamine, $22 \%$ from the $\alpha$-amino group of amino acids, and $35 \%$ from arterial ammonia $(4,32)$. Comparable assessments for rat or man are not available (33), although it has been estimated that $63 \%$ of the ammonia produced by the kidney of man is contributed by the amide nitrogen of glutamine (32).

Several investigators have tested the effect of adding glutamate or aspartate on ammonia production by kidney slices or the perfused kidney (34-39). In these experiments it is difficult to judge how much ammonia arises from the added substrate and how much from endogenous sources such as glutamine. In all cases addition of aspartate or glutamate caused an enhancement of ammonia production. The concentrations of glutamate or aspartate that were added were very high compared to their normal extracellular concentrations. Comparison of normal kidneys with kidneys from acidotic animals shows that in all cases the latter exhibited higher rates of ammonia production $(22,34-40)$.

Table I shows that the specific activities of adenylosuccinate synthetase and adenylosuccinase in kidneys of normal rats were 1.2 and $1.3 \mathrm{nmol} / \mathrm{mg}$ protein per min respectively. These activities rose to 1.9 and 3.3 , respectively, in rats fed ammonium chloride. The specific activity of adenylate deaminase in kidneys from ammonium chloride-fed rats sets an upper limit to ammonia production by this enzyme of $26 \mathrm{nmol} / \mathrm{mg}$ protein per min. These activities are of the order of magnitude ${ }^{3}$ of

\footnotetext{
${ }^{3}$ The rates found in the literature were converted to nanomoles per milligram cytoplasmic protein per minute by using the following conversion factors. Rates expressed per gram fresh weight of kidney were converted to rates per
}

the rates of ammonia production reported in the literature $(22,34-40)$. A comparison of the rates of ammonia production reported for intact rats $(22,40)$ with the activities of adenylosuccinate synthetase and adenylosuccinase (Table I) shows that these enzymes can account for 10-100\% of ammonia production in normal rats and for $7-64 \%$ in acidotic rats. In view of the wide range of rates of ammonia production reported in the literature, and the uncertainty concerning the contribution made by the amide group of glutamine, these figures indicate that in the kidney the purine nucleotide cycle may account for a substantial portion of ammonia production from $\alpha$-amino groups of $\alpha$-amino acids.

Our results also show that kidney extracts catalyze the conversion of IMP to inosine and uric acid (Fig. 3). The loss of purine nucleotides into nucleosides and purine bases is probably initiated by alkaline phosphatase, since it cannot be prevented by adenosine $\alpha, \beta$-methylene diphosphonate (AOPCP), a powerful inhibitor of $5^{\prime}$-nucleotidase (14). The contribution that the mammalian kidney makes to an animal's total uric acid production has not been assessed previously. The conversion of IMP to uric acid is inhibited by either allopurinol or 1-pyrophosphoryl ribose 5-phosphate, while the production of ammonia via the purine nucleotide cycle is markedly increased by these substances (Figs. 3 and 4). The simplest explanation for this finding is that uric acid production constitutes a drain on the pool of purine nucleotides that catalyze the production of ammonia via the purine nucleotide cycle, and that allopurinol and 1pyrophosphoryl ribose 5-phosphate block this drain. Clinical observations have linked ammonia and uric acid production in gout $(42,43)$. Compared to controls, patients with primary gout may excrete $30 \%$ less ammonia in the urine (44), and they have elevated blood levels of glutamate (45). Our studies indicate that ammonia and uric acid production in the kidney may be linked via the purine nucleotide cycle. IMP can either

milligram cytoplasmic, nonparticulate protein by multiplying by 70 . The amount of cytoplasmic, nonparticulate protein per gram fresh weight of kidney was determined experimentally by a method reported previously (41), and was found to be $70 \mathrm{mg}$ protein per $\mathrm{g}$ fresh weight. (The enzyme activities measured in Table II are found largely and possibly exclusively in the soluble cytoplasm.) The average wet weight to dry weight ratio for rat kidney was determined to be 3.92; this factor was used to convert results expressed per gram dry weight of kidney to results per gram wet weight. The activities quoted in Table II are per minute, whereas most rates of ammonia production in the literature are quoted per hour or longer; appropriate corrections were applied to obtain the same time base. Some results in the literature are expressed per $100 \mathrm{~g}$ body weight; to convert these to per gram fresh weight of kidney, we used a value of $0.82 \mathrm{~g}$ kidney per $100 \mathrm{~g}$ body weight. Appropriate corrections were also made to convert results expressed in millimole and micromole to nanomole. 
participate catalytically in the purine nucleotide cycle or be dissipated to form urate. The factors that control the relative rates at which these two pathways operate in vivo remain to be determined.

\section{ACKNOWLEDGMENTS}

We gratefully acknowledge the assistance of Keith Tornheim, Vera Schultz, Karen Steele, and Gretchen Bean.

This work was supported in part by U. S. Public Health Service grants AM-11793 and GM-07261.

\section{REFERENCES}

1. Pitts, R. F. 1972. Symposium on acid-base homeostasis. Control of renal production of ammonia. Kidney Int. 1 : 297-305.

2. Van Slyke, D. D., R. A. Phillips, P. B. Hamilton, R. M. Archibald, P. H. Futcher, and A. Hiller. 1943. Glutamine as source material of urinary ammonia. J. Biol. Chem. 150: 481-482.

3. Pitts, R. F., L. A. Pilkington, and J. C. M. de Haas. 1965. $\mathrm{N}^{15}$ tracer studies on the origin of urinary ammonia in the acidotic dog, with notes on the enzymatic synthesis of labeled glutamic acid and glutamines. $J$. Clin. Invest. $44:$ 731-745.

4. Pitts, R. F. 1968. Physiology of the Kidney and Body Fluids. Year Book Medical Publishers Inc., Chicago. 2nd edition. 202.

5. Lowenstein, J. M. 1972. Ammonia production in muscle and other tissues: The purine nucleotide cycle. Physiol. Rev. 52: 382-414.

6. Goodman, A. D., R. E. Fuisz, and G. F. Cahill, Jr. 1966. Renal gluconeogenesis in acidosis, alkalosis, and potassium deficiency. Its possible role in regulation of renal ammonia production. J. Clin. Invest. 45: 612-619.

7. Tornheim, K., and J. M. Lowenstein. 1972. The purine nucleotide cycle. The production of ammonia from aspartate by extracts of rat skeletal muscle. J. Biol. Chem. 247: 162-169.

8. Lowry, O. H., N. J. Rosebrough, A. L. Farr, and R. J. Randall. 1951. Protein measurement with the Folin phenol reagent. J. Biol. Chem. 193: 265-275.

9. Brown, H. 1945. The determination of uric acid in human blood. J. Biol. Chem. 158: 601-608.

10. Kalckar, H. M. 1947. Differential spectrophotometry of purine compounds by means of specific enzymes. I. Determination of hydroxypurine compounds. J. Biol. Chem. 167 : 429-443.

11. Seligson, D., and H. Seligson. 1951. A microdiffusion method for the determination of nitrogen liberated as ammonia. J. Lab. Clin. Med. 38: 324-330.

12. Hohorst, H-J. 1963. L- (+)-Lactate. Determination with Lactic Dehydrogenase and DPN. In Methods of Enzymatic Analysis. H-U. Bergmeyer, editor. Academic Press, Inc., New York. 266-270.

13. Williamson, J. R., and B. E. Corkey. 1969. Assays of intermediates of the citric acid cycle and related compounds by fluorometric enzyme methods. Methods Enzymol. 13: 434-513.

14. Burger, R. M., and J. M. Lowenstein. 1975. 5'-Nucleotidase from smooth muscle of small intestine and from brain. Inhibition by nucleotides. Biochemistry. 14 : 23622366.

15. Simpson, D. P. 1972. Pathways of glutamine and organic acid metabolism in renal cortex in chronic metabolic acidosis. J. Clin. Invest. 51: 1969-1978.
16. Bourke, E., A. Fine, and J. Scott. 1971. Mechanisms of ammoniagenesis in human kidney. Biochem. J. 125: 94P. (Abstr.)

17. Goldstein, L. 1967. Pathways of glutamine deamination and their control in the rat kidney. Am.J. Physiol. 213: 983-989.

18. Goldstein, L., R. Richterich-Van Baerle, and E. $H$. Dearborn. 1957. Kidney gluatminases. II. The glutamine$\alpha$-keto acid transamination-deamidation system of the guinea pig. Enzymologia. 18: 261-270.

19. Richterich, R. W., and L. Goldstein. 1958. Distribution of glutamine metabolizing enzymes and production of urinary ammonia in the mammalian kidney. $A m$. $J$. Physiol. 195: 316-320.

20. Welbourne, T. C., and S. Balagura-Baruch. 1972. Renal metabolism of glutamine in dogs during infusion of $\alpha$-ketoglutaric acid. Am. J. Physiol. 222: 663-666.

21. Pagliara, A. S., and A. D. Goodman. 1970. Relation of renal cortical gluconeogenesis, glutamate content, and production of ammonia. J. Clin. Inv'est. 49: 1967-1974.

22. Alleyne, G. A. O., and G. H. Scullard. 1969. Renal metabolic response to acid base changes. I. Enzymatic control of ammoniagenesis in the rat. J. Clin. Invest. 48: 364-370.

23. Preuss, H. G. 1968. Pyridine nucleotides in renal ammonia metabolism. J. Lab. Clin. Med. 72: 370-382.

24. Preuss, H. G., and F. R. Weiss. 1971. Rate-limiting factor in rat kidney slice ammoniagenesis. Am. J. Physiol. 221 : 458-464.

25. Preuss, H. G., F. R. Weiss, and S. Adler. 1971. Renal ammonia production in the presence of citric acid cycle blockade. Proc. Soc. Exp. Biol. Med. 136: 738-741.

26. LéJohn, H. B. 1968. Unidirectional inhibition of glutamate dehydrogenase by metabolites. A possible regulatory mechanism. J. Biol. Chem. 243: 5126-5131.

27. De Haan, E. J., J. M. Tager, and E. C. Slater. 1967. Factors affecting the pathway of glutamate oxidation in rat-liver mitochondria. Biochim. Biophys. Acta. 131: 1-13.

28. Tornheim, K., and J. M. Lowenstein. 1975. The purine nucleotide cycle. Control of phosphofructokinase and glycolytic oscillations in muscle extracts. J. Biol. Chem. 250: 6304-6314.

29. Schultz, V., and J. M. Lowenstein. 1976. Purine nucleotide cycle. Evidence for the occurrence of the cycle in brain. J. Biol. Chem. 251: 485-492.

30. Snedecor, G. W., and W. G. Cochran. 1971. Statistical Methods. Iowa State University Press, Ames. 7th edition. 93.

31. Engel, A. G., C. S. Potter, and J. W. Rosevear. 1964. Nucleotides and adenosine monophosphate deaminase activity of muscle in primary hypokalaemic periodic paralysis. Nature (Lond.). 202: 670-672.

32. Pitts, R. F. 1973. Production and excretion of ammonia in relation to acid-base regulation. Renal physiology. Handb. Physiol. 8 : 455-496.

33. Relman, A. S., and R. G. Narins. 1975. The control of ammonia production in the rat. Med. Clin. North Am. 59: 583-593.

34. Kamm, D. E., and G. L. Strope. 1972. The effects of acidosis and alkalosis on the metabolism of glutamine and glutamate in renal cortex slices. J. Clin. Invest. 51: 1251-1263.

35. Freed, K. H., C. Bowie, O. Vavatsi-Manos, and H. G. Preuss. 1973. Oxygen consumption and ammoniagenesis in rat kidney slices. Am. J. Physiol. $224: 268-270$. 
36. Vavatsi-Manos, O., D. M. Roxe, G. E. Schreiner, and H. G. Preuss. 1973. $\gamma$-Aminobutyric acid shunt in renal ammoniagenesis. Am. J. Physiol. 224: 154-157.

37. Hems, D. A. 1972. Metabolism of glutamine and glutamic acid by isolated perfused kidneys of normal and acidotic rats. Biochem. J. $130: 671-680$.

38. Pitts, R. F. 1971. Metabolism of amino acids by the perfused rat kidney. Am. J. Physiol. 220: 862-867.

39. Welbourne, T. C. 1974. Ammonia production and pathways of glutamine metabolism in the isolated perfused rat kidney. Am. J. Physiol. 226: 544-548.

40. Goorno, W. E., F. C. Rector, Jr., and D. W. Seldin. 1967. Relation of renal gluconeogenesis to ammonia production in the dog and rat. Am. J. Physiol. 213: 969-974.
41. Spencer, A., L. Corman, and J. M. Lowenstein. 1964. Citrate and the conversion of carbohydrate into fat. A comparison of citrate and acetate incorporation into fatty acids. Biochem. J. 93: 378-388.

42. Gutman, A. B., and T-F. Ÿ̈. 1963. On the nature of the inborn metabolic error(s) of primary gout. Trans. Assoc. Am. Physicians. Phila. 76: 141-151.

43. Gutman, A. B., and T. F. Ÿ̈. 1963. An abnormality of glutamine metabolism in primary gout. Am. J. Med. $35: 820-831$.

44. Falls, W. F., Jr. 1972. Comparison of urinary acidification and ammonium excretion in normal and gouty subjects. Metab. Clin. Exp. 21: 433-445.

45. Gutman, A. B., and T-F. Yü. 1973. Hyperglutamatemia in primary gout. Am. J. Med. 54: 713-724. 